\title{
Comparing the Health Risks of Alfalfa Sprouts and Wheatgrass via Detecting the Presences of Escherichia coli in their Juices
}

\author{
Cathy Wong $^{1}$, Bobby Sidhu ${ }^{2}$, Lorraine McIntyre ${ }^{3}$, and Ken Keilbart ${ }^{4}$ \\ ${ }^{1}$ Lead Author, B. Tech Student, School of Health Sciences, British Columbia Institute of Technology, \\ 3700 Willingdon Ave, Burnaby, BC V5G 3H2 \\ ${ }^{2}$ Supervisor, School of Health Sciences, British Columbia Institute of Technology, 3700 Willingdon Ave, \\ Burnaby, BC V5G 3H2 \\ ${ }^{3}$ Contributor, BC Centre for Disease Control, 655 West 12th Avenue, Vancouver, British Columbia, V5Z \\ 4R4 \\ ${ }^{4}$ Lab Technician, School of Health Sciences, British Columbia Institute of Technology, 3700 Willingdon \\ Ave, Burnaby, BC V5G 3H2
}

\begin{abstract}
Background: Past studies have analyzed the health risks associated with alfalfa sprout production and developed standard procedures to reduce foodborne illnesses. There have been no studies related to microgreen outbreaks, specifically wheatgrass. Wheatgrass has become a growing culinary trend and the potential health risks associated need to be evaluated. Alfalfa sprouts and wheatgrass both share the same initial growth production - pre-soak and germination. The only difference is the harvesting period. This paper evaluated the risks associated with alfalfa sprout production and compared it with wheatgrass production by contaminating both alfalfa sprouts and wheatgrass with $E$. coli The presences of $E$. coli in the plant's juices were evaluated and compared. Method: Alfalfa sprouts and wheatgrass were grown in similar conditions, in hydroponic condition, with an additional wheatgrass in soil. The plants were grown and harvested according to its respective pre-soaking and harvesting period, as specified by the Canadian Food Inspection Agency. The plants were inoculated with Escherichia coli during the germination period, and then juiced to examine the presences of $E$. coli within its internal structure. The Hygiena systemSURE II luminometer was used to detect the presences of E. coli via the MicroSnap ${ }^{\mathrm{TM}}$ Enrichment and E. coli detection swabs. Results: The result showed that $E$. coli was present in both wheatgrass and alfalfa sprouts juice. The root systems of the food products were independent of each other. The types of growth medium used for wheatgrass were also independent of each other. Conclusion: The study found that growing microgreens should be treated similarly to sprout productions. Food facilities with wheatgrass production need to be aware of safe handling, production, and storage of wheatgrass to prevent foodborne illnesses.
\end{abstract}

Key words: wheatgrass, microgreens, sprouts, foodborne illness, E. coli, root system, contamination

\section{Introduction}

The past few years, a particular microgreen called wheatgrass has become a hot culinary trend. The difference between microgreens compared to sprouts and baby greens are based on their harvesting point (Wigmore, 1985). Consequently, in understanding the consumption of the various harvesting point during plant development, one can assume the majority of the potential health risks arise from sprouts. Numerous Escherichia coli (E. coli) outbreaks have been associated with sprouts and salad greens, but very limited documentation of outbreaks have been associated with microgreens. Microgreens, particularly wheatgrass have become a growing trend of being added into smoothies and drinks due to its highly packed nutritional value. However, the potential risks associated with wheatgrass have not been thoroughly investigated.

\section{Literature Review \\ What is Wheatgrass?}

Wheatgrass juice has become a popular trend in today's health and diet food. Wheatgrass comes from the common wheat plant, Triticum aestivum, which belongs to the Poaceae family (Bodla \& Mujoriya, 2011). It is a young grass that is packed with vitamins, minerals and nutrients that are beneficial for the body (Wigmore, 1985). Fifteen pounds of wheatgrass juice has a comparable nutritional value as 350 pounds of leafy greens and vegetables (Bodla, \& Mujoriya, 2011). These benefits include blood purification, liver detoxification, antioxidant, colon cleansing, healing wounds, and etc.

(Belger, 2008). The health claims of wheatgrass juice have garnered attention and taken towards a healthier lifestyle. 
To fully absorb all the nutrients in wheatgrass, wheatgrass must be juiced rather than blended or eaten (Belger, 2008). The difference between juicing and blending is that "juicing is a process which extracts water and nutrients from [a] produce and discards the indigestible fiber" (Boutenko, 2009); whereas, blending is a process that includes the "entire fruit or vegetable, skin and contains all of the fiber" (Boutenko, 2009). Juicing allows an easier digestion of the nutrients that is readily absorbed because the body does not have to break down the food (Shermer, 2008). For this reason, wheatgrass juice is consumed on its own or integrated into smoothies or drinks to add an extra boost to a healthier lifestyle (Boutenko, 2009). Wheatgrass juice can be consumed by anyone, even individuals who have wheat allergies. Wheat allergies respond to gluten, which is found in the seed rather than the grass; hence, the juice is deemed safe for consumption (Gilbere, 2003).

\section{Outbreaks Related to Sprouts}

There have been numerous sprout-related foodborne outbreaks associated with $E$. coli O157. For example, in 1997, a multistate outbreak of 108 cases of E. coli O157:H7 was reported in Michigan and Virginia (Breuer, Benkel, Shaprio, Hall, Winnett, Linn, et al. 2001). Epidemiological studies associated the $E$. coli O157:H7 outbreak with contaminated alfalfa sprouts and trace-back investigation revealed that the sprouts were produced at a single sprouting facility (U.S Food and Drug Administration [FDA], 1999b). The farm that harvested the alfalfa seeds was reported to have several sources of contamination. In general, seeds in farms can be contaminated with animal manure, runoff of irrigation water or unhygienic practices (Health Canada, 2006). For this reason it is required for seed processors to abide to Good Agricultural Practices (GAP) to prevent microbial, chemical, and physical contamination of seeds during production (Canadian Food Inspection Agency [CFIA], 2007).

\section{Legislation and Regulations}

In Canada, the Canadian Food Inspection Agency (CFIA) enforces the Food and Drugs Act and regulations for the production of sprouts. Health Canada establishes the microbial standards for sprouting facilities. Since sprouts are considered high-risk foods, sprouting facilities must conduct multiple laboratory tests for the presences of pathogenic bacteria (CFIA, 2007). Overall, during all stages of sprout production, the sprouting facilities must safeguard and prevent any potential introduction of pathogenic bacteria to the sprouts to reduce the risk of illnesses. However, whether microgreens are pre-grown or seeds delivered to food establishments, the standard for safe handling of microgreen production at food establishments are not addressed.

Potential Risks During Sprouting Process Individuals who consume raw or slightly cooked sprouts are at risk of exposure to harmful pathogens, such as E. coli (Health Canada, 2011). The onset symptoms of $E$. coli infections occur within one to ten days of consuming contaminated food. Symptoms may include vomiting, fever, bloody diarrhea, and stomach cramps. More serious symptoms include hemolytic uremic syndrome (HUS), kidney damage and death. Seniors, young children and the immune-compromised are more at risk of serious health issues related to foodborne illnesses (Health Canada, 2011). Thus, to reduce the risk of sprout-related illnesses, individuals should avoid eating raw sprouts altogether.

Consequently, understanding the health risks associated with consumptions of raw sprouts, it cannot be certain that the consumption of raw microgreens poses the same health risks. The possibility of microgreens harboring pathogens is still of concern. Even though microgreens are grown in different environments than sprouts, it is without a doubt that some health risks still occurs, as they can be consumed raw. In addition, since microgreens and sprouts both mature from the seeded state, the potential introduction of pathogens during seed development is still of interest. Thereby, in understanding the potential hazards that can occur during the sprouting process, one can compare the health risks affiliated with microgreens.

\section{Seeds}

In many studies, epidemiological investigation suggested that the primary sources of contamination of sprouts are from the seeds (Taormina, Beuchat, \& Slutsker, 1999). Seeds intended for sprouting are considered raw agricultural commodities. This increases the exposure of seeds to fecal contamination during the growing process, such as manure applied, irrigation and runoff water, and animal feces (Thompson \& Powell, 2000). Other contaminants that may be introduced during seed production are from: chemical applications, land 
usage, worker's hygiene, harvesting, scarification, packaging, and transportation (CFIA, 2007). Majority of the seeds grown on agricultural parcels are used for animal feed, and only a small portion of seeds are sprouted for human consumption; hence, GAP from seed processors during seed production are strongly recommended to protect contamination of mixing sprouting seeds with animal feed seeds (Thompson \& Powell, 2000).

If pathogens are present on the sprouting seed, it will likely survive for a prolonged time (Thompson \& Powell, 2000). Health Canada (2006) suggested that to reduce pathogens on seeds a method would be to sanitize them. While disinfecting seeds is recognized as an essential part of producing safer sprouts, studies have shown that the disinfection process does not remove all pathogens (FDA, 2013). Pathogens can still remain within the cracks and crevices of the seeds (University of Guelph, 2013; Health Canada, 2006).

\section{Sprouts}

The sprouting process poses a special risk, in which the germination environment is not only optimal for sprouting but also for pathogen growth. This can lead to foodborne illnesses, as there are no inherent kill steps to eliminate pathogens on sprouts (Thompson \& Powell, 2000).

Sprouts are considered high-risk, and ready-toeat food without further processing or kill step (FDA, 1999a). It has been documented that microbial flora, coliforms and fecal coliforms, on the seeds or during sprouting process grow exponentially (above $10^{7}$ per grams of sprout) due to the ideal germination conditions temperature, moisture, and growing time (FDA, 1999b). Data has shown that the levels of microbial flora on sprouts were 2 to 3 logs higher than on the seeds (Thompson \& Powell, 2000). More specifically, alfalfa seeds inoculated with $E$. coli were shown to have bacteria proliferate from $10^{6}$ to $10^{7} \mathrm{cfu} / \mathrm{g}$ within 48 hours of germination (Thompson \& Powell, 2000).

Therefore, in understanding the proliferation of $E$. coli in alfalfa seeds during sprouting process, one can compare it with wheatgrass seeds. The ideal germination conditions for alfalfa sprouts corresponds with wheatgrass seeds. Hence, if studies have found that $E$. coli proliferated from $10^{6}$ to $10^{7} \mathrm{cfu} / \mathrm{g}$ within 48 hours of germination on alfalfa seeds, then one can deduce that wheatgrass seeds are similar. Consequently, the chance of wheatgrass being contaminated during sprouting process is greater due to its prolonged germination period before it is harvested, and its potential exposure to poor environmental conditions, such as improper storage.

Additionally, studies have shown that E. coli 0157:H7 can be established on the internal root structures of sprouts from entry gains into the cracks and fissures during roots emergence (Warriner, Spaniolas, Dickinson, Wright, \& Waites 2003). A study done by Warriner et al. (2003) confirmed that E. coli was found within the stem or hypocotyls of sprouts; thus, the chance that $E$. coli being internalized and distributed throughout the sprouts is likely. This becomes questionable because if sprouts' roots are able to internalize and distribute $E$. coli with the plant, then the health risks of consuming raw microgreens are significant.

Likewise, in relation to this research project, the presences of $E$. coli within their plant structure in alfalfa sprouts and wheatgrass were compared. If studies found that sprouts were able to uptake E. coli through their root structure from the environment, then possibility that the uptake of contaminants present in the soil or irritation water during wheatgrass growth, poses significant health concerns. As mentioned earlier, sprouts are considered high-risk and ready-to-eat foods; hence, in comparison to wheatgrass production, it would also be considered a high-risk food. Therefore, this research project assessed the health risks that may be associated with wheatgrass as compared to alfalfa sprouts, and if standard procedures during wheatgrass production needs to be addressed.

\section{Sprouting Control}

Due to the high-risk nature of sprouts, sprout operators are advised to have a Hazard Analysis and Critical Control Point (HACCP) system in place to reduce the risk of unsafe food and to control food hazards during the appropriate stages of the sprouting process (CFIA, 2007). HACCP allows operators to take preventative measures of critical control points (CCP) to ensure the end products are safe and suitable for human consumption.

\section{Sprouting Process}


All steps involved in the sprouting process should be carried out diligently to avoid contamination. To better grasp the health risks that can be associated with microgreens, one needs to understand the sprouting process.

\section{Microgreen Growth - Wheatgrass}

Growing microgreens takes a different approach than sprouts. Microgreens can be planted and grown in soil rather than hydroponically. If all precautionary steps leading up to the planting of microgreens' seeds into the soil are abided to, the growth of microgreens should have minimal foodborne risks. For the purpose of this paper, the microgreen for discussion is wheatgrass, as it is a growing phenomenon in the food industry and any health risks associated should be addressed.

The ideal conditions for wheatgrass to grow are high exposures to light, low humidity levels, and good air circulation. This is necessary and important in creating chlorophyll and reducing mold growth (Dégraff, 2011). Wheatgrass are grown in trays or mats to preserve its quality when delivered to food establishments (Treadwell et al., 2013). Unlike sprouts, these growing conditions for wheatgrass are not ideal for pathogen proliferation. The wheatgrass are then cooled and stored in recommended temperatures to minimize potential pathogen growth (Treadwell et al. 2013).

If one were to grow wheatgrass indoors within their establishment, such as juice bars, the health risks associated with contamination of pathogens become a concern. Although growing wheatgrass indoors allow control over environmental conditions, the planted seeds should come from reputable sources (Franks \& Richardson 2009). Indoor plantation requires soil for the growth of wheatgrass, which increases the likelihood of health risks (Franks \& Richardson, 2009). It is recommended that growers follow proper hygienic practices and use only potable water when watering plants or misting (Wigmore, 1985). Wheatgrass is to be kept away from any contamination such as debris or chemical aerosol, and be refrigerated when not in use (Franks \& Richardson, 2009). When wheatgrass is about seven inches tall, it is ready for harvest (Dégraff, 2011). The wheatgrass is cut five centimeters above the seeds, washed and then juiced to obtain the most nutrients before it matures and develop grains. Consequently, the consumption of wheatgrass has no apparent kill step. As Warrnier et al. (2003) mentioned in their study, if roots are able to internalize pathogens into their hypocotyl and allowed to develop, then the probability of microgreen-related foodborne illness is indicative. Hence, this research project compared the similar growth stages of alfalfa sprouts and wheatgrass, and assessed if contamination will be present during consumption.

\section{Purpose}

The purpose of this research project was to determine if there are any risks associated with the presences of $E$. coli in wheatgrass juice versus alfalfa sprouts juice. If there have been documented cases of sprouts-related outbreaks caused by contaminated seeds, then the potentiality that microgreen grown from contaminated seeds may link to health risks. Since wheatgrass has become a popular trend in the food industry due to its many health benefits, there has been limited data on outbreaks associated with wheatgrass. Therefore, to explore this association, alfalfa seeds and wheatgrass seeds were inoculated with $E$. coli during the germination stage, when their root structures were developed, to examine the presences of $E$. coli in the juices.

$\mathrm{Ho}_{1}$ : E.coli uptake in root system is independent of whether it is wheatgrass or alfalfa (both in water)

$\mathrm{Ha}_{1}$ : E.coli uptake in root system is dependent of whether it is wheat grass or alfalfa (both in water)

$\mathrm{Ho}_{2}$ : E.coli uptake in a wheatgrass root system is independent of growth medium (soil or water)

$\mathrm{Ha}_{2}$ : E.coli uptake in a wheatgrass root system is dependent of growth medium (soil or water)

\section{Role of an Environmental Health Officer}

In understanding the health risk of sprouts, it can also be affiliated with wheatgrass; hence, Environmental Health Officers (EHOs) need to ensure that during inspections of food service establishments, proper growing, handling, and storage of wheatgrass are adhered to, to prevent any foodborne illness from occurring. EHOs need to ensure that staff members handling wheatgrass understand proper hand hygiene practices and handling procedures to prevent contamination. 


\section{Methods}

This research project compared the health risks associated with wheatgrass juice versus alfalfa sprouts juice by detecting the presences or absence of $E$. coli in their juices. The wheatgrass were grown in two conditions - hydroponic and soil media and were compared with the alfalfa sprouts grown in hydroponic condition. The alfalfa seeds and wheatgrass seeds were inoculated during the germination stage, when their root structures were developed, and then juiced during their harvesting stage to examine the presences of $E$. coli of each product. The Hygiena systemSURE II luminometer was used to detect the presences of $E$. coli via the MicroSnap ${ }^{\mathrm{TM}}$ Enrichment and E. coli detection swabs.

\section{Results \\ Descriptive Statistics}

The descriptive statistics showed that E. coli was present in all the conditions of wheatgrass and alfalfa sprouts juice (Figure 1).

\section{Inferential Statistics}

The inferential statistic results the p-value of the Pearson's Chi-Square test for $\mathrm{Ho}_{1}$ was 1.000 (Hintze, 2013). The p-value was greater than 0.05 , which was not statistically significant at the $5 \%$ level; therefore, the null $\left(\mathrm{Ho}_{1}\right)$ hypothesis was not rejected. It concluded that $E$. coli uptake in the root system was independent of whether it was wheatgrass or alfalfa sprouts in the water growth medium.

The p-value of the Pearson's Chi-Square test for $\mathrm{Ho}_{2}$ was also 1.000. Therefore the null hypothesis $\left(\mathrm{Ho}_{2}\right)$ was not rejected, which concluded that $E$. coli uptake in the wheatgrass root system was independent of the growth medium, in either soil or water (Hintze, 2013.

\section{Discussion}

Based on previous researches on foodborne illnesses associated with sprouts, GAP was strongly recommended to protect contamination of seeds and guidelines were produced to address sanitary practices during sprouting process. However, there was lack of evidence to support that microgreens can also be affected by poor handling practices from food handlers. As mentioned before, a study done by Warrnier et al. (2003) showed that sprouts were able to internalize $E$. coli through its root system; hence, in understanding the growth stages of microgreens, the chances of microgreens internalizing $E$. coli into its root system is very likely. Microgreens are grown similarly to sprouts, with the exception of the harvesting stage; therefore, microgreens can be treated like sprouts as a high-risk, ready-to-eat food.

The results from this study showed that $E$. coli uptake from the root system was independent of whether it was wheatgrass or alfalfa sprouts and the growth medium (soil or water) used were independent of each other. This stressed the importance that sprouts production and microgreens production are correlated and have the potentially of being contaminated. Nonetheless, proper handling practices must be addressed and acknowledged by food handlers during microgreen production at food establishments to prevent foodborne illnesses. However, more research is needed to examine the difference in E. coli amounts present in the juices of the food products to further understand the relationship between sprouts and microgreens.

If food establishments are starting to grow their own wheatgrass on the premise, they should be aware of the risks related to poor handling. It is crucial that food handlers understand that in a warm and moist environment during the sprouting process, potable water is used during germination and irrigation to prevent $E$. coli proliferation and being up-taken into its root system. If soil media was used for wheatgrass production, the soil should be pasteurized to eliminate any potential contamination. It should also not be ignored that wheatgrass requires an extended length of time before harvesting; hence, the potential for $E$. coli proliferation will increase. Consequently, food establishments need to ensure that during wheatgrass growth, they store it in an area away from possible contamination and refrigerated when not in use.

As previously mentioned, the CFIA enforces the Food and Drugs Act and regulations on sprout production where the potential for commination is high. However, due to the extended growth phase of wheatgrass, the chance of recontamination at food premises becomes a concern and CFIA does not focus on the latter stage. This makes it a great opportunity for EHOs to elaborate on making guidelines or standards tailored to the food establishment in growing their own wheatgrass. These guidelines will include proper control and handling of sprouting process, wheatgrass growth, and 
Figure 1. Descriptive Statistics

\begin{tabular}{ccc}
\hline & Absence & Presence \\
\hline Sprouts & 1 & 9 \\
Wheatgrass - H2O & 1 & 9 \\
Wheatgrass - Soil & 1 & 9 \\
\hline
\end{tabular}

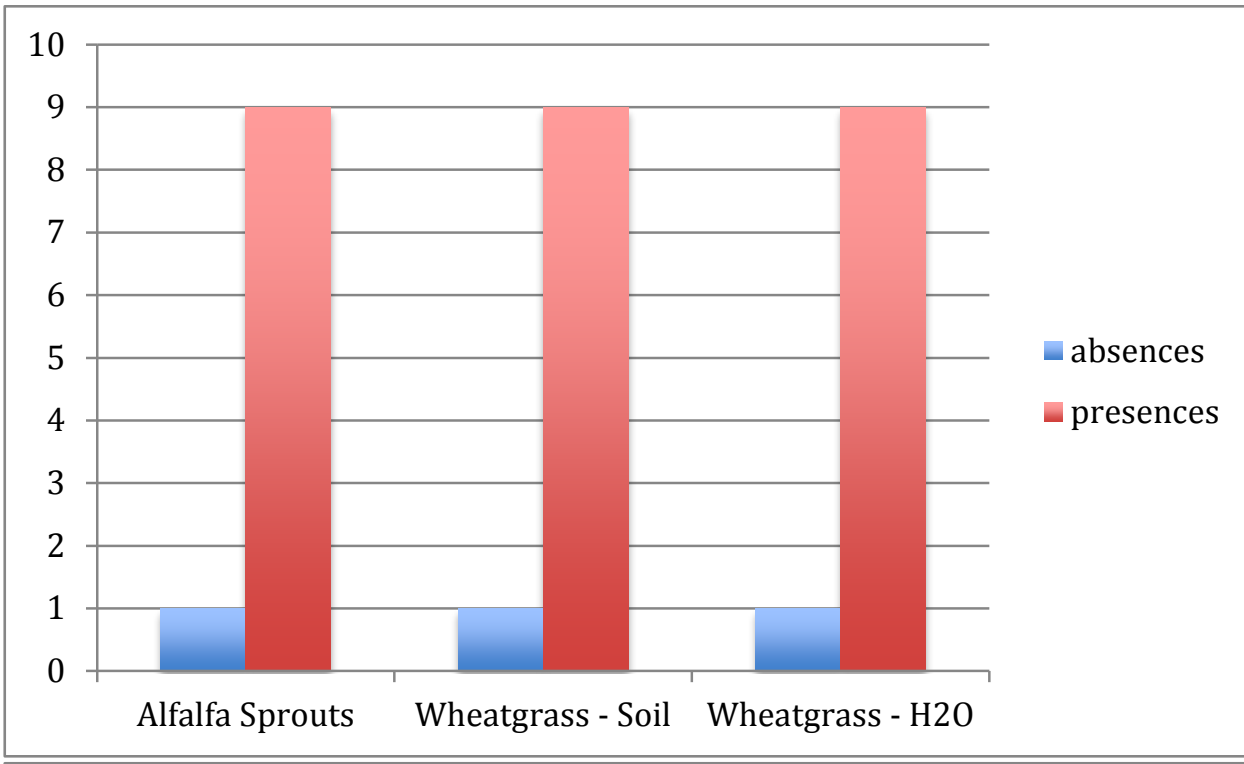

\section{Presences}

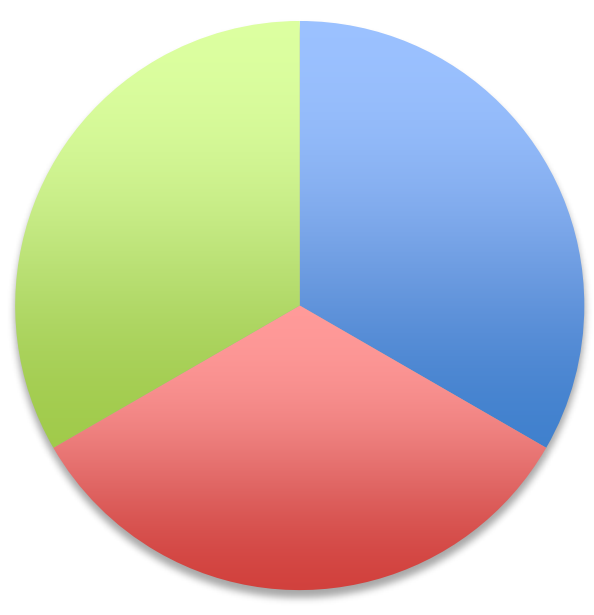

- Alfalfa Sprouts

Wheatgrass - H2O

Wheatgrass - Soil 
processing the wheatgrass into juice. This will further reduce the likelihood of food borne illnesses from ever occurring when consuming wheatgrass juice. Furthermore, EHOs, can also recommend food establishments to create Food Safety Plans, addressing the standard operating procedures to reduce possible contamination of the juice product from farm to juicer. Therefore, due to the growing trend of wheatgrass juice, it is preferable to treat wheatgrass similar to sprouts to prevent outbreaks. It should also be noted that daily cleaning of the juicer is recommended to ensure adequate disinfectant of the cracks and crevices to prevent build up and a medium for pathogen harborage.

The pre-grown wheatgrass delivered to food establishments should be aware that the operators understand the risks associated with watering, handling and storing of wheatgrass on the premise. If wheatgrass are stored on the ground or in display case where customers are able to have contact, the chance of contamination can result. Operators that juice wheatgrass cut an inch above the soil and gently dip the cut ends in water before it gets juiced. The water used to mist and to rinse the ends need to be potable water. Food handlers need to also ensure that cups used to receive dispensed juice are clean and sanitized. All process leading up to the juicing should be controlled for to minimize any risk of contaminating the wheatgrass juice, specifically the critical control point would be the early stages of growing the wheatgrass, which has a higher chance of being contaminated with pathogens. Using potable water, pasteurized soil and disinfected seeds and trays are crucial in preventing food borne illnesses from consuming wheatgrass juice.

\section{Limitations}

The limitations of the study that may have affected the results are the following:

1. Washing the juicer more thoroughly and effectively to reduce the chances of contaminating the other test results. This can be achieved by sanitizing in between uses with one parts chlorine and ten parts water and air-drying after.

2. Washing the wheatgrass and alfalfa sprouts more thoroughly before juicing to reduce the chance of $E$. coli on the exterior of the food products to affect the results.

3. Increasing time in conducting the study so more food product can be produced for sampling to reduce possible errors.
4. Budget constraints have limited the availability of detection swab supplies, therefore limited the number of samples.

5. The detection swabs used were newly confirmed by AOAC of detecting presences or absences of E.coli. This project was one of the first few test subjects to have used the detection swabs. If the detection swabs are more recognized, the results will be more accepted.

\section{Recommendation}

Based on the results of this project, some recommendations that would be helpful is to have CFIA include wheatgrass production into its regulations along with the sprouts regulations. The recommendation in the lens of an EHO's would be to request operators for food safety plans regarding safe handling of wheatgrass during production, storage, and processing. Wheatgrass production should be treated similarly to sprouts production, since both food products have no inherent kill step associated before consumption. The results of this project stressed the importance of having safe potable water during wheatgrass production at the food premise, regardless of the growth medium used, since $E$. coli is capable of being up-taken in the root system. It also stressed the importance that the soil being used to grow wheatgrass needs to be pasteurized to prevent contamination, if potable water was used. It is recommended that food handlers are aware that poor food handling of wheatgrass production to processing can contribute to food borne illnesses.

\section{Future Research}

For future research studies regarding this project would be to compare if there are any significant differences in the amount of $E$. coli present in wheatgrass and alfalfa sprout juices by enumeration. By comparing the difference in $E$. coli amount between the two food products, it can help produce guidelines for safe handling of wheatgrass.

Another future research would be to conduct a survey to food premises that offers juicing of wheatgrass. The survey would analyze food handlers' knowledge on safe handling procedures for wheatgrass production, storage, and processing. Alternatively, another research can address that if potable water was used for growing and irrigation, would E. coli still be uptaken by the root system via unpasteurized soil contaminated with E. coli. And lastly, a future research can also address if there are any 
significant differences in the amount of $E$. coli present between rinsing the whole cut wheatgrass versus the rinsing the end tips.

\section{Conclusion}

In conclusions, the results of this project showed that $E$. coli was able to be up-taken into the root systems regardless of whether it was wheatgrass or alfalfa sprouts or the growth medium that was used - in water or soil. The results found that potable water must be used during the growing process of wheatgrass in food premises to prevent food borne illnesses from occurring. It should be noted that wheatgrass production should be treated similarly to sprout production; therefore, EHOs would need to set up guidelines or standards to ensure safe handling of wheatgrass production at food facilities for food handlers.

\section{Competing Interest}

The author declares that she has no competing interest in the research topic beyond the scope of this course.

\section{References}

Belger, M. (2008). Natural healing. Natural Health, 38(2). 87-89.

Bodla, B.R., \& Mujoriya, R. (2011). A study on wheat grass and its nutritional value. Food Science and Quality Management, 2, 1-9

Boutenko, V. (2009). Green smoothie revolution: the radical leap towards natural health.

USA: North Atlantic Books

Breuer, T., Benkel, D.H., Shaprio, R.L., Hall, W.N., Winnett, M.M., Linn, M.J., et al. (2001). A multistate outbreak of Escherichia coli O157:H7 infections linked to alfalfa sprouts grown from contaminated seeds. Emerging Infectious Diseases Journal, 7(6). Retrieved from http://wwwnc.cdc.gov/eid/article/7/6/010609.htm

Canadian Food Inspection Agency. (2007). Code of practice for the hygienic production of sprouted seeds. Retrieved from http://www.inspection.gc.ca/english/fssa/frefra/ safsal/sprointe.shtml

Dégraff, L.R. (2011). The complete guide to growing and using wheatgrass. Florida:
Atlantic Publishing Group.

Franks, E., \& Richardson, J. (2009). Microgreens: a guide to growing nutrient-packed greens. China: Gibbs Smith.

Gilbere, G. (2003). Nature's immune booster and pH balancer. Total Health, 25(4). 40-41.

Green Harvest Organic Gardening Supplies. (n.d). Green harvest sprouting, wheatgrass and microgreen guide. Retrieved from http://greenharvest.com.au/DownLoads/Sprouti ngBooklet.pdf

Health Canada. (2006). Policy on managing health risk associated with sprouted seeds and beans. Retrieved from http://www.hcsc.gc.ca/fnan/legislation/pol/sprouts_pol_pousses-eng.php

Health Canada. (2011). Risks associated with sprouts. Retrieved from http://www.hcsc.gc.ca/hl-vs/iyh-vsv/food-aliment/sproutsgermes-eng.php

Hintze, J. (2013). NCSS 9. NCSS, LLC. Kaysville, Utah, USA. www.ncss.com.

Hygiena. (2005). Calibration control rod kit. Retrieved from http://www.hygiena.net/calibration_kit.html

Hygiena. Direction for use of Micro-Snap - rapid determination of coliform and E. coli. (2011). Retrieved from http://www.scigiene.com/pdfs/MicroSnap\%20 Coliform\%20E\%20coli\%20Insert.pdf

Hygiena. (2013). Microsnap ${ }^{\mathrm{TM}}$ rapid microorganism detection. Retrieved from http://www.hygiena.net/docs/MicroSnap_Broc hure_RevA042013_email.pdf

Hygiena. (n.d.a). Pi-102. Retrieved from http://www.hygiena.net/docs/pi102.pdf

Hygiena. (n.d.b). SystemSure plus. Retrieved from http://www.hygiena.net/docs/SS3_brochure.pdf

Jeter, C., \& Matthysse, A.G. (2005). Characterization of the binding of diarrheagenic strains of E.coli to plant surfaces and the role of curli in the interaction of the bacteria with alfalfa sprouts. The 
American Phytopathological Society, 18(11). 1235-1242.

Microsoft. (2011a). Microsoft Excel (Version 14.1.0). Microsoft Corporation.

Microsoft. (2011b). Microsoft Word (Version 14.1.0). Microsoft Corporation.

Rana, S., Kamboj, K.J., Gandhi, V. (2011). Living life the natural way - wheatgrass and health. Functional Foods in Health and Disease, 1(11). 444-456. Retrieved from http://www.functionalfoodscenter.net/files/494 61571.pdf

Shermer, M. (2008). Wheatgrass juice and folk medicine. Scientific American, 299(2). 42.

Taormina, P.J., Beuchat, L.R., Slutsker, L. (1999). Infections associated with eating seed sprouts: an international concern. Emerging Infectious Diseases Journal, 5(5). 626-632. Retrieved from http://www.ncbi.nlm.nih.gov/pmc/articles/PM C2627711/pdf/10511518.pdf

Thompson, S., \& Powell, D.A. (2000). Risks associated with the consumption of fresh sprouts. International Specialty Supply. Retrieved from http://www.sproutnet.com/Research/risks_asso ciated_with_the_consum.htm

Treadwell, D.D., Hochmuth, R., Landrum, L., \& Laughlin, W. (2013). Microgreens: a new specialty crop. Horticultural Science. Retrieved from http://edis.ifas.ufl.edu/hs1164
University of Guelph. Food Science Network. (2013). Sprouts. Retrieved from https://www.uoguelph.ca/foodsafetynetwork/sp routs

U.S. Food and Drug Administration. (1999a). Guidance for industry: Reducing microbial food safety hazards for sprouted seeds. Retrieved from http://www.fda.gov/food/guidanceregulation/g uidancedocumentsregulatoryinformation/produ ceplantproducts/ucm120244.htm

U.S. Food and Drug Administration. (1999b). Microbiological safety evaluations and recommendations on sprouted seed. Retrieved from http://www.fda.gov/Food/FoodborneIllnessCon taminants/BuyStoreServeSafeFood/ucm078789 .htm\#ecoli

U.S. Food and Drug Administration. (2013). Growing sprouts in retail food establishments CFP Issues 02-III-01 and 04-III-012. Retrieved from http://www.fda.gov/food/guidanceregulation/re tailfoodprotection/ucm078758.htm

Warriner, K., Spaniolas, S., Dickinson, M., Wright, C., \& Waites, W.M. (2003). Internalization of bioluminescent Escherichia coli and Salmonella Montevideo in growing bean sprouts. Journal of Applied Microbiology, 95,719-727. doi:10.1046/j.1365-

2672.2003.02037.x

Wigmore, A. (1985). The wheatgrass book. USA: Penguin. 